Review

\title{
Nanoparticles for Radiation Therapy Enhancement: the Key Parameters
}

\author{
Paul Retif1,2,3, Sophie Pinel2,3, Magali Toussaint2,3, Céline Frochot ${ }^{4,5, \#, ~ R i m a ~ C h o u i k r a t ~}{ }^{4,5}$, Thierry \\ Bastogne $2,3,6, \#$, Muriel Barberi-Heyob2,3,\#,,$\triangle$ \\ 1. CHR Metz-Thionville, Hôpital de Mercy, Service de radiothérapie, 1 allée du Château, Ars-Laquenexy, 57530, France; \\ 2. Université de Lorraine, CRAN, UMR 7039, Campus Sciences, BP 70239, Vandœuvre-lès-Nancy Cedex, 54506, France; \\ 3. CNRS, CRAN, UMR 7039, Vandœuvre-lès-Nancy Cedex, 54506, France; \\ 4. Université de Lorraine, LRGP, UMR 7274, 1 rue Grandville, Nancy, 54000, France; \\ 5. CNRS, LRGP, UMR 7274, 1 rue Grandville, Nancy, 54000, France; \\ 6. Université de Lorraine, INRIA-BIGS \& CRAN, BP 70239, Vandœuvre-lès-Nancy Cedex, 54506, France. \\ \# CNRS, GdR 3049 Photomed, France.
}

$\triangle$ Corresponding author: +33 (0)3 83683208 : muriel.barberi@univ-lorraine.fr; CRAN UMR 7039 CNRS, Département SBS, Faculté de Médecine -

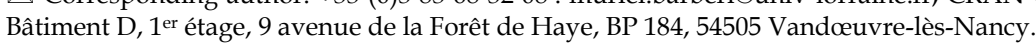

(C) 2015 Ivyspring International Publisher. Reproduction is permitted for personal, noncommercial use, provided that the article is in whole, unmodified, and properly cited. See http:/ /ivyspring.com/terms for terms and conditions.

Received: 2015.01.20; Accepted: 2015.03.26; Published: 2015.06.11

\begin{abstract}
This review focuses on the radiosensitization strategies that use high-Z nanoparticles. It does not establish an exhaustive list of the works in this field but rather propose constructive criticisms pointing out critical factors that could improve the nano-radiation therapy. Whereas most reviews show the chemists and/or biologists points of view, the present analysis is also seen through the prism of the medical physicist. In particular, we described and evaluated the influence of X-rays energy spectra using a numerical analysis. We observed a lack of standardization in preclinical studies that could partially explain the low number of translation to clinical applications for this innovative therapeutic strategy. Pointing out the critical parameters of high- $Z$ nanoparticles radiosensitization, this review is expected to contribute to a larger preclinical and clinical development.
\end{abstract}

Key words: Cancer; Nanoparticles; Radiation therapy; Radiobiology; Radiosensitization; Photodynamic therapy.

\section{Introduction}

Nanomedicine is based on drug delivery using organic nanomaterials as nanocarriers [1]. Inorganic-based nanomaterials are mostly developed for other health care applications such as in vitro diagnosis and in vivo imaging. For example, magnetic nanoparticles (NP) are used for cell sorting applications in clinical diagnosis or magnetic resonance imaging (MRI) [2]. More recently, nanomaterials have been developed to play a pivotal therapeutic role by their own. A prominent illustrative example is NPs-based magnetic hyperthermia being developed for the treatment of cancer by the startup Magforce. In this treatment, aminosilane-coated magnetic NPs are injected into the tumor and subsequently heated with a newly developed magnetic field applicator in order to induce apoptotic cell death [3].

Over the last decades, many research programs dealt with in vitro and in vivo applications of NPs in radiation therapy. Given that radiation therapy is not a selective antitumor treatment, the main challenge for radiation oncologists, medical physicists and radiobiologists is to increase its therapeutic efficacy without increasing damages dealt to the surrounding healthy tissues. Hence, the goal of combining NPs 
with radiation therapy is to increase the differential effect between healthy and tumor tissues.

Different mechanisms of interaction between X-rays and NPs are expected according to NPs chemical nature. We could distinguish between (i) high atomic number Z, NPs that enhance the photoelectric and Compton effects (and thus the subsequent emissions of secondary electrons) to increase conventional radiation therapy efficacy; (ii) X-ray triggered drug-releasing NPs that, for instance, uses drug-loaded NP [4]. Under irradiation, the NP capsule is destroyed and the drug is released inside the targeted tissues. (iii) Self-lighting photodynamic NPs that are usually made of a lanthanide-doped high-Z core [5]. Once irradiated by X-rays, the scintillator core emits a visible light and activates a photosensitizer that generates singlet oxygen $\left({ }^{1} \mathrm{O}_{2}\right)$ for tumor destruction. These NPs combine both photodynamic therapy (PDT) that generates reactive oxygen species (ROS) and enhanced radiation therapy (high- $Z$ core).

The present review focuses on the radiosensitization strategies that use high-Z NPs. In this context, these NPs can intensify the production of secondary electrons and ROS that in turn enhance radiation therapy effects. The most studied NPs are gold-based NPs (GNPs) that were widely described in particular by Hainfeld et al. [6]. Recent studies have also reported the use of lanthanide-based NPs, titanium oxide nanotubes or cadmium selenide quantum dots [7-10]. For example, gadolinium-based NPs, besides their high-Z, offer an innovative approach due to their capacity to act as powerful contrast agents in MRI [11]. Interestingly, some authors used silver-based NPs to take advantage of its excellent surface enhanced Raman scattering and broad-spectrum antimicrobial activities [12].

There are only few NPs available on the market which is probably a consequence of the difficulties to create large-scale production with adapted characterizations and the high-cost of the whole process. In a recent review, Coulter et al. [13] highlight the gap between the wealth of preclinical data supporting high-Z NPs as effective radiosensitizers and the low number of clinical studies (indeed only one phase I clinical trial) and regret the lack of rigorous and systematic methodologies to evaluate NPs efficacy. In agreement with this observation, we focused on the critical parameters that could influence the radiosensitizing power of nanoparticles and methods used to assess the radiosensitizing properties of high- $Z$ nanoparticles in silico, in vitro and in vivo.

The aim of this review is not to establish for the first time an exhaustive list of the works in this field but rather propose constructive criticisms pointing out critical factors that could improve the nano-radiation therapy strategies. While most reviews show the chemists and/or biologists points of view, the present analysis is also seen through the prism of the medical physicist.

We have studied 64 papers that mentioned the words radiation therapy (or radiotherapy) and nanoparticles during the period late 2008 - 2014. In our meta-analysis, we have distinguished on one side, the factors unrelated to nanoparticle, and on the other, parameters depending on the nanoparticle design. Notably, we have carried out a numerical analysis to assess the influence of the irradiation source by measuring the dose modifying factor on survival curves for in vitro studies which used clinical X-rays only (no isotopes, ions, synchrotron or electron beams). Furthermore, this paper describes the multi-scale impact of nanoparticle design, as it could determine the interaction probability with ionizing radiations (we considered X-rays only), the capacity to generate ROS and the cellular localization or tissue distribution of NPs.

\section{How to measure the nanoparti- cles-mediated improvement?}

In this part, following the description of recommended methods to measure in vitro radiation therapy efficacy, we will detail three approaches to assess the enhancement of radiation therapy efficacy by NPs: (i) the determination of the Dose Modifying Factor (DMF) based on survival curves, (ii) the determination of the Nanoparticle-mediated Enhancement Ratio (NER) after a single radiation dose and (iii) the variation of the ROS production upon irradiation.

When possible, the DMF should be chosen over the NER which can be seen as a "special case" of the DMF where only one irradiation dose had been applied. The measurement of the ROS production can be done alone or in addition to the DMF/NER evaluation in order to find which lethal effects are prevailing.

\section{In vitro assessment of radiation therapy effect}

In radiation therapy, clinically relevant dose of radiation generate DNA damage that could lead to early cell death but rather result in cell death after one or more cell divisions. Hence, a cell is "radiobiologically dead" only if its reproductive integrity is lost. In vitro, the gold standard to evaluate the cytotoxicity of ionizing radiations is the clonogenic assay (also called CFU assay for Colony Forming Unit) as it tests every cell in the population for its ability to undergo unlimited division, thus taking into account the "cell reproductive death" [14]. Results of clonogenic assay are generally plotted as "survival curves" which represent the fraction of surviving cells as a function of 
the dose (typically 0 to $10 \mathrm{~Gy}$ ). The linear-quadratic (LQ) model is the most common representation used to fit the experimental curves and to describe cell survival. For a single fraction at a dose $D$ [Gy], the fraction of surviving cells $S$ is described by the LQ model as:

$$
S=e^{-\left(\alpha D+\beta D^{2}\right)}
$$

where $a$ and $\beta$ are two model parameters. The LQ model also allows the estimation of the SF2 parameter that describes the survival fraction at $2 \mathrm{~Gy}$, i.e. a dose fractionation widely used in clinical practice for curative treatments. Even though the LQ model is widely used in radiation therapy studies, it is also still controversial [15]. Moreover, it was not proven that the LQ model could describe dose-effect relations in the presence of NPs and it should therefore be used with care.

\section{Measurement of the DMF on survival curves}

To evaluate the efficacy increase in classical radiation biology, it is customary to use the Relative Biological Effectiveness (RBE) which is defined as the ratio of a dose of standard radiation (e.g. photons) to a dose of any other type of ionizing particles (i.e. protons, neutron, etc) to produce the same biological effect [16]. The RBE is clinically relevant as it could allow clinicians to adapt the delivered doses according to the performances of the new therapeutic system or strategy, in comparison to conventional treatments. For example, medical physicists and radiation oncologists would have to deliver 30 Gy with NPs instead of delivering $60 \mathrm{~Gy}$, if the therapeutic strategy "X-rays with NPs" was characterized by a RBE of 2 . The concept of RBE has already been discussed by the International Commission on Radiological Protection (ICRP) [17] and the International Commission on Radiation Units \& Measurement (ICRU) [18].

The RBE is very close to the concept of DMF that applies to radiosensitizers or radioprotectors and should be useful and relevant with NPs. As defined by the International Atomic Energy Agency (AIEA) [19], the DMF is:

$D M F=\frac{\text { Dose to produce an effect with radiosensitizer / radioprotector }}{\text { Dose to produce the same effect without radiosensitizer / radioprotector }}$

Typically, in vitro experiments yielding to survival curves and LQ model parameters are suitable and useful to determine the DMF.

For example using the results of Jain et al. [20] who irradiated MDA-MB-231 cells with a 6 MV accelerator, we measured a SF2 of $72.3 \%$. Then we observed that the dose in presence of $1.9 \mathrm{~nm}$ GNPs, which lead to a survival fraction of $72.3 \%$, is 1.39 Gy. Therefore the DMF calculated from this particular set of results is equal to 0.695 . As the DMF is inferior to 1 , the GNPs used by Jain et al. have an in vitro radiosensitizing power at $6 \mathrm{MV}$ regarding MDA-MB-231 breast cancer cells.

\section{Measurement of the NER (mono-dose)}

Even though the DMF is a relevant parameter for clinical practice, it is not systematically available in preclinical studies that evaluate and compare the radiosensitizing properties of specific NPs. Indeed, the DMF determination implies to test different doses of radiations and this approach is not always feasible, in particular in in vivo studies. Some authors have just compared biological effects induced by X-ray therapy in presence or absence of NPs for a single radiation dose. In these cases, only the "NP-mediated" Enhancement Ratio (NER, by similarity to the well-known oxygen enhancement ratio) is available [21].

As an illustration, Xiao et al. [22], evaluated the viability of Hela cells after an exposition to multifunctional core/satellite nanotheranostics followed by an irradiation of $6 \mathrm{~Gy}$. We measured that the cell viability without nanotheranostics after a 6 Gy irradiation was $88 \%$. The viability for $600 \mu \mathrm{g} / \mathrm{mL}$ of nanotheranostics after a 6 Gy irradiation was $69 \%$. Therefore the NER for this result is 0.784 .

\section{Measurement of ROS}

Although the role of ROS in the treatment of cancer is controversial, the evaluation of their production could bring new information concerning the radiosensitizing effect of the studied NPs.

Because of the high sensitivity and the simplicity in data collection, some authors [23-25] have chosen to assess the radiosensitizing power of NPs by measuring variations in the production of ROS upon irradiation. To assess that, authors have conducted experiments in solution (water or other solvent) or in vitro using chemical probes that fluoresce in presence of ROS. Fluorescence was commonly monitored using fluorescence spectroscopy or microscopic imaging techniques due to their high spatial resolution.

For example, Takahashi et al. proved the improvement of ROS generation of their CdSe NPs under irradiation using hydroethidine-dihydroethidium (DHE) which is a reagent that is converted to ethidium on reaction with ROS such as $\mathrm{O}_{2}^{-\cdot}$ and $\mathrm{OH}$. Generation of ROS was observed as a function of $X$-rays doses in aqueous solution, and its amount depended on the concentration of NPs [9]. More recently, Townley et al. evaluated the formation of ROS by their titanium NPs after irradiation in water using coumarin that reacts with ROS to generate highly fluorescent 7-hydroxycoumarin. In the absence of NPs they observed no fluorescence. In the presence of NPs, 
bright fluorescence indicated ROS production [26]. Few authors described results that followed the same tendency [13, 27-29].

According to the chemical probe chosen, authors have focused on different ROS. Misawa et al. reported the use of the chemical probe aminophenyl fluorescein (APF) to analyze the GNP-induced enhancement of $\mathrm{OH}$ as this fluorescein derivative yield a bright green-fluorescent product when it reacts with ${ }^{1} \mathrm{O}_{2}$ or $\mathrm{OH}$. [24]. Similarly, Gara et al. [25] used phenol (PhOH), furfuryl alcohol (FFA) and histidine (HIS) as scavengers to evaluate the ROS formation of silicon NPs. They showed that the NPs are capable of enhancing the yields of $\mathrm{O}_{2}^{-} \cdot / \mathrm{HO}_{2}$ and $\mathrm{OH}$ in aqueous suspensions as a consequence of X-rays absorption. Moreover, ${ }^{1} \mathrm{O}_{2}$ is formed in irradiated solutions only in the presence of the NPs.

Among the 64 papers we analyzed, 7 papers are dealing with the in vitro evaluation of ROS. They all used the cell-permeable fluorogenic probe DCFH-DA, commonly known as dichlorodihydrofluorescin, supplied as the diacetate ester. It is used as an indicator of ROS. Following enzymatic or base-catalyzed cleavage of the diacetate groups, it is readily oxidized to the highly fluorescent product dichlorofluorescein (DCF).

\section{Parameters not depending on nanoparti- cles design}

The present paragraph focuses on nanoparticle-independent parameters that can significantly alter the radiosensitizing power of NPs, i.e.: (i) the biological evaluation methodologies, (ii) the energy of the incident photon beam and (iii) the irradiation setup.

\section{Biological evaluation methodology}

Consistently with classical experimental methods in radiobiology, lot of authors performed clonogenic assays to compare the cytotoxicity of radiations with or without NPs [9, 30-33]. Chang et al., Liu et al. and Butterworth et al. reported radiation dose-survival curves, allowing the comparison of response profiles, while Chang et al., Roa et al., Rima et al. and Coulter et al. tested only one dose of radiation. Most of studies focused on results obtained after 2 Gy-irradiation as this dose is consistent with radiotherapy clinical fractionation [31, 32, 34]. To evaluate the radiosensitizing effect of NP, other biological tests such as viable cell count using Trypan blue, metabolic assays, apoptosis detection, or $\mathrm{\gamma H}_{2} \mathrm{AX}$ foci detection were also reported, alone and instead of clonogenic assays, or in addition and in comparison to them. It is noteworthy that in many cases, these biological tests have been conducted before clonogenic assays and applied to NP alone. Metabolic assays used were mainly based on the enzymatic reduction of tetrazolium dye (MTT, MTS, WST-1) but also on the resazurin sodium salt reduction (Alamar blue test) [21]. Except in Liu et al. study, articles concluded to a reduced cell viability rate when irradiation was combined with NP exposure [32]. When comparison was possible, results of metabolic assays and clonogenic assays were concordant [28, 31, 35, 36]. Even though the "time" was not systematically mentioned, it is noteworthy that these metabolic tests could have been performed at different time post-irradiation. According to whether they were made in short- or long-term after irradiation, the results obtained do not reflect the same mechanisms of cell loss. Indeed, Mowat et al. that have measured cell viability 7 days post-irradiation have included the radiation-induced mitotic cell death [37], while several works only considered the cell death occurring in the first $24 \mathrm{~h}$ or $48 \mathrm{~h}$ $[31,35]$.

Few authors have also investigated cell apoptosis to compare radiation cytotoxicity with or without NP exposure. Cell apoptosis have been detected by flow cytometry after Annexin-FITC staining $[28,38]$ or by identifying the sub-G1 population [13, 31]. Authors demonstrated an increase in cell apoptosis when irradiated cells were in contact with NP.

Instead of or in complement with methods to evaluate cell survival, many authors have compared the radiation-induced DNA damage in presence or absence of NP. Experiments were based on the detection of DNA double-strand breaks as they are the most lethal lesions. To do that, differential plasmid DNA migration on agarose gel electrophoresis [39, 40] and comet assays [41] have been reported. More frequently, foci of $\gamma \mathrm{H} 2 \mathrm{AX}$ and/or foci of 53BP1 which are well-known as markers of DNA double strand breaks were detected by immunofluorescence techniques. In fine, the interpretation of results remains difficult because of the heterogeneity of protocols used. In some studies, authors have fixed cells rapidly post-irradiation and have thus investigated the number of radiation-induced lesions while in other cases $[32,42]$, authors have followed the capacity of cells to repair DNA double strand breaks, assuming that only unrepaired lesions could cause cell death [43].

In vivo experiments aiming to evaluate the radiosensitizing potential of NPs have been performed using tumor xenografts in immunodeficient rodents and tumor growth or animal survival have been followed [11, 38, 44-46]. In case of NP with imaging application, orthotopic models, notably intracranial xenografts were preferred as they are more relevant than subcutaneous ones $[11,46]$. According to studies, the route of NP administration differed: intratumoral 
injection reported by Maggiorella et al. or Chattopadhyay et al. allowed to overcome the problems of biodistribution $[42,45]$; by contrast, for intravenous or intraperitoneal administrations $[38,46]$ it could be necessary to optimize the drug-irradiation interval [11]. Generally, irradiation to treat tumor-bearing animals was delivered as a single dose comprised between 5 and 35 Gy [46, 47]. Only Maggiorella et al. have tested a fractionated schedule ( $2 \times 4$ Gy) [45].

Histological observation and immunohistochemical analysis have been carried out to illustrate treatment-induced cell death. Especially, the TUNEL assay allowing the apoptosis detection has been reported [30, 45].

\section{The energy of the incidents $X$-rays (source)}

In X-ray external radiation therapy, low energy beams (until $200 \mathrm{kV}$ ) have very few applications and are dedicated to skin treatments $(<5 \mathrm{~mm}$ in depth, e.g. melanoma, basal cell carcinoma, squamous cell carcinoma, keloid) (Fig. 1). Medium energies $200 \mathrm{kV}$ to 1 MV (orthovoltage and supervoltage $\mathrm{X}$-rays) were widely used for shallow treatments since the 1930's 1940 's but became less advantageous at the advent of high-energy electrons during the 1960's - 1970's. Nowadays, high-energy beams, also called megavoltage beams, ( 1 to $25 \mathrm{MV}$ ) are by far the most commonly used as they allow the treatment of deep tumors ( $>2 \mathrm{~cm}$ in depth).

As the impact of the beam energy on the RBE (without NPs) has already been shown [48], it is then legitimate to ask whether the beam energy would have an impact on the radiosensitizing properties of high-Z-NPs. Cell damages following interactions between $X$-rays and high-Z NPs mostly result from the photoelectric effect which is prevailing until the photon energy reaches $500 \mathrm{keV}$ (e.g. for $\mathrm{Au}$ ). As a consequence, one could conclude that the radiosensitizing effect of these NPs should be stronger for low-energy beams. However, radiation therapy beams are poly-energetic, and high-energy spectra have a low-energy component which triggers photoelectric effects. Moreover the medium- and high-energy components should theoretically interact with matter (here in high-Z NPs and biological matter) by Compton effect, therefore releasing lower energy photons. These latter, depending on their energy, trigger in turn either photoelectric or Compton effects. That is why a substantial radiosensitizing effect of high-Z NPs can be expected for high-energy beams.

In order to assess this crucial question, we have carried a numerical analysis only based on in vitro results; corresponding studies have been summarized in Table 1. Indeed, among the publications that we studied, 18 evaluated the radiosensitizing effect of NPs using an analytical method or a Monte Carlo simulation algorithm (MCNP5, MCNPX, Geant4, PENELOPE or EGSnrc) often comparing $\mathrm{kV}$ and MV photons. We did not take them into account because Butterworth et al. [33] have already shown that in vitro experiments did not fit early physical predictions. Even though, we reported these publications in the Table 2.

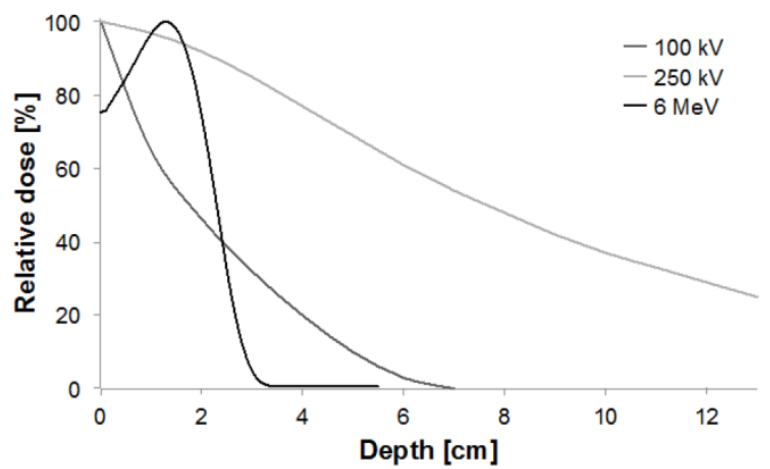

Figure 1. Depth-dose curves normalized at the depth of maximum for $100 \mathrm{kV}, 250$ $\mathrm{kV}$ and $6 \mathrm{MeV}$ beams ( $\mathrm{kV}=$ photons, $\mathrm{MeV}=$ electrons).

Table 1. In vitro or in vivo experiments dealing with the radiation therapy enhancement by nanoparticles.

\begin{tabular}{|c|c|c|c|c|c|c|}
\hline REFERENCE & EXPERIMENTS & PARTICLE & SOURCE & MATERIAL & $\begin{array}{l}\text { SIZE (range; nm) } \\
{[\mathrm{nm}]}\end{array}$ & DMF \\
\hline [43] & In vitro & Y & 125I & $\mathrm{Au}$ & 50 & \\
\hline [34] & In vitro & Not Applicable & Not Applicable & $\mathrm{Gd}$ & 5 & \\
\hline [26] & In vitro & $\mathrm{X}$ & $250 \mathrm{kV}$ & $\mathrm{Ti}$ & 65 & \\
\hline [41] & In vitro & $x$ & $40 \mathrm{kV}$ & $\begin{array}{l}\mathrm{Fe} \\
\mathrm{Bi}\end{array}$ & $\begin{array}{l}10 \\
30\end{array}$ & \\
\hline [46] & In vivo & $x$ & $100 \mathrm{kV}$ & $\mathrm{Au}$ & 10 & \\
\hline [42] & $\begin{array}{l}\text { In vitro } \\
\text { In vivo }\end{array}$ & $x$ & $100 \mathrm{kV}$ & $\mathrm{Au}$ & 30 & 0.74 \\
\hline [38] & $\begin{array}{l}\text { In vitro } \\
\text { In vivo }\end{array}$ & r & ${ }^{137} \mathrm{Cs}$ & $\mathrm{Au}$ & $4.8-46.6$ & \\
\hline [45] & $\begin{array}{l}\text { In vitro } \\
\text { In vivo }\end{array}$ & $X$ or $\gamma$ & $\begin{array}{l}{ }^{60} \mathrm{Co} \\
6 \mathrm{MV}\end{array}$ & Hf & 50 & 0.765 \\
\hline [13] & In vitro & $x$ & $160 \mathrm{kV}$ & $\mathrm{Au}$ & 1.9 & \\
\hline [11] & In vivo & X (synchrotron) & $50-350 \mathrm{keV}$ & $\mathrm{Gd}$ & 2 & \\
\hline [28] & In vitro & $x$ & $90 \mathrm{kV}$ & $\mathrm{Au}$ & 14 & \\
\hline
\end{tabular}




\begin{tabular}{|c|c|c|c|c|c|c|}
\hline & & & $6 \mathrm{MV}$ & & & \\
\hline [79] & In vitro & Electrons & $60 \mathrm{keV}$ & $\mathrm{Au}$ & $5-13$ & \\
\hline \multirow[t]{8}{*}{ [20] } & In vitro & $\mathrm{X}$ or Electrons & $160 \mathrm{kV}$ & $\mathrm{Au}$ & 1.9 & 0.499 \\
\hline & & & $6 \mathrm{MV}$ & & & 0.695 \\
\hline & & & $15 \mathrm{MV}$ & & & 0.695 \\
\hline & & & $6 \mathrm{MeV}$ & & & 0.706 \\
\hline & & & $16 \mathrm{MeV}$ & & & 0.718 \\
\hline & & & & & & 0.745 \\
\hline & & & & & & 0.776 \\
\hline & & & & & & 1.18 \\
\hline [21] & In vitro & $\mathrm{x}$ & $6 \mathrm{MV}$ & $\mathrm{Au}$ & 50 & \\
\hline \multirow[t]{2}{*}{ [37] } & In vitro & $\mathrm{x}$ & $660 \mathrm{kV}$ & $\mathrm{Gd}$ & 5 & \\
\hline & & & $6 \mathrm{MV}$ & & & \\
\hline [80] & In vitro & $\mathrm{x}$ & $200 \mathrm{kV}$ & $\mathrm{Au}$ & Not Applicable & \\
\hline \multirow[t]{5}{*}{ [32] } & In vitro & $\mathrm{X}$ or Protons & $6.5 \mathrm{keV}$ & $\mathrm{Au}$ & 6.1 & 0.354 \\
\hline & & & $45 \mathrm{kV}$ & & & 0.411 \\
\hline & & & $160 \mathrm{kV}$ & & & 0.496 \\
\hline & & & $6 \mathrm{MV}$ & & & \\
\hline & & & $3 \mathrm{MeV}$ & & & \\
\hline \multirow[t]{8}{*}{ [81] } & In vitro & $x$ & $160 \mathrm{kV}$ & $\mathrm{Au}$ & 1.9 & 0.46 \\
\hline & & & & & & 0.516 \\
\hline & & & & & & 0.908 \\
\hline & & & & & & 0.949 \\
\hline & & & & & & 0.977 \\
\hline & & & & & & 1 \\
\hline & & & & & & 1.17 \\
\hline & & & & & & 1.22 \\
\hline [82] & In vivo & X (synchrotron) & $\begin{array}{l}20-190 \mathrm{keV} \\
80-300 \mathrm{keV}\end{array}$ & $\mathrm{Au}$ & 1.9 & \\
\hline [83] & In vitro & Carbon ions & $276 \mathrm{MeV} / \mathrm{amu}$ & $\mathrm{Pt}$ & 3 & \\
\hline [84] & In vitro & X (synchrotron) & $80 \mathrm{kV}$ & $\mathrm{Au}$ & 2 & \\
\hline \multirow[t]{3}{*}{ [50] } & In vitro & $x$ & $40 \mathrm{kV}$ & $\mathrm{Au}$ & 37.5 & \\
\hline & & & $80 \mathrm{kV}$ & & & \\
\hline & & & $120 \mathrm{kV}$ & & & \\
\hline \multirow[t]{5}{*}{ [40] } & In vitro & $\mathrm{x}$ & $30 \mathrm{kV}$ & $\mathrm{Au}$ & 8 & 0.2 \\
\hline & & & $80 \mathrm{kV}$ & & 20 & 0.25 \\
\hline & & & $100 \mathrm{kV}$ & & 37 & 0.5 \\
\hline & & & $120 \mathrm{kV}$ & & 74 & \\
\hline & & & $150 \mathrm{kV}$ & & 92 & \\
\hline \multirow[t]{4}{*}{ [49] } & In vitro & $\mathrm{X}$ or Electrons & $80 \mathrm{kV}$ & $\mathrm{Au}$ & 1.9 & 0.1 \\
\hline & & & $150 \mathrm{kV}$ & & & 0.221 \\
\hline & & & $6 \mathrm{MeV}$ & & & \\
\hline & & & $12 \mathrm{MeV}$ & & & \\
\hline [31] & In vitro & $\gamma$ & ${ }^{137} \mathrm{Cs}$ & $\mathrm{Au}$ & 10.8 & \\
\hline [85] & In vitro & y & ${ }^{137} \mathrm{Cs}$ & $\mathrm{La}$ & 10 & \\
\hline \multirow[t]{3}{*}{ [30] } & In vitro & $X$ or $Y$ & $200 \mathrm{kV}$ & $\mathrm{Au}$ & 10.8 & \\
\hline & In vivo & & ${ }^{60} \mathrm{Co}$ & & & \\
\hline & & & ${ }^{137} \mathrm{Cs}$ & & & \\
\hline [86] & In vitro & $x$ & $6 \mathrm{MV}$ & $\mathrm{Au}$ & 4.7 & \\
\hline \multirow[t]{2}{*}{ [87] } & In vitro & $\gamma$ or carbon ions & ${ }^{60} \mathrm{Co}$ & $\mathrm{Au}$ & 1.9 & \\
\hline & & & $62 \mathrm{MeV}$ & & & \\
\hline [52] & In vitro & $\mathrm{x}$ & $105 \mathrm{kV}$ & $\mathrm{Au}$ & 50 & \\
\hline & & & $220 \mathrm{kV}$ & & & \\
\hline & & & $6 \mathrm{MV}$ & & & \\
\hline [88] & In vitro & $x$ & $6 \mathrm{MV}$ & $\mathrm{Au}$ & 13 & \\
\hline [89] & In vitro & $\mathrm{X}$ (synchrotron) & $50 \mathrm{keV}$ & $\mathrm{Au}$ & 1.9 & \\
\hline & In vivo & & $88 \mathrm{keV}$ & & 15 & \\
\hline [90] & In vitro & $x$ & $100 \mathrm{kV}$ & $\mathrm{Bi}$ & 50 & \\
\hline [91] & In vitro & $x$ & $150 \mathrm{kV}$ & $\mathrm{Au}$ & 23 & 0.66 \\
\hline & In vivo & & $175 \mathrm{kV}$ & & & \\
\hline [8] & In vitro & $x$ & $6 \mathrm{MV}$ & $\mathrm{Ti}$ & 10 & 0.627 \\
\hline & & & & & & 0.637 \\
\hline [7] & In vivo & $x$ & $200 \mathrm{kV}$ & $\mathrm{Ti}$ & 10 & \\
\hline [23] & In vitro & $\mathrm{x}$ & $120 \mathrm{kV}$ & $\mathrm{Fe}$ & $3-20$ & \\
\hline [25] & In vitro & $\mathrm{x}$ & $4 \mathrm{MV}$ & $\mathrm{Si}$ & 3 & \\
\hline [24] & In vitro & $x$ & $100 \mathrm{kV}$ & $\mathrm{Au}$ & $5-250$ & \\
\hline [27] & In vitro & $x$ & $6 \mathrm{MV}$ & Not Applicable & 48 & \\
\hline [47] & In vitro/In vivo & $x$ & $6 \mathrm{MV}$ & $\mathrm{Au}$ & $28.9-47$ & \\
\hline [10] & In vitro & $x$ & $6 \mathrm{MV}$ & CdSe & 25 & 0.631 \\
\hline [92] & In vitro & $x$ & $150 \mathrm{kV}$ & $\mathrm{Ce}$ & 7 & \\
\hline & & & $10 \mathrm{MV}$ & & & \\
\hline [9] & In vitro & $x$ & $100 \mathrm{kV}$ & CdSe & 10 & \\
\hline$[51,61]$ & In vitro & X (synchrotron) & $30-100 \mathrm{keV}$ & $\mathrm{Au}$ & 1.9 & \\
\hline [61] & In vitro & $x$ & $120 \mathrm{kV}$ & $\mathrm{Au}$ & 1 & \\
\hline
\end{tabular}


Table 2. Analytical or Monte Carlo calculations concerning the radiation therapy enhancement by nanoparticles.

\begin{tabular}{|c|c|c|c|c|c|}
\hline REFERENCE & CODE & PARTICLE & SOURCE & MATERIAL & SIZE [nm] \\
\hline [55] & GEANT4 & $\mathrm{X}$ & $\begin{array}{l}150 \mathrm{kV} \\
15 \mathrm{MV}\end{array}$ & $\mathrm{Au}$ & Not Applicable \\
\hline [93] & MCNP5 & $X$ or $Y$ & $\begin{array}{l}{ }^{125 \mathrm{I}} \\
{ }^{169} \mathrm{Yb} \\
{ }^{192} \mathrm{Ir} \\
50 \mathrm{kV}\end{array}$ & $\mathrm{Au}$ & 1.9 \\
\hline [94] & EGSnrc & $X$ or $Y$ & $\begin{array}{l}{ }^{103} \mathrm{Pd} \\
{ }^{125} \mathrm{I} \\
169 \mathrm{Yb} \\
{ }^{192} \mathrm{Ir} \\
50 \mathrm{kV} \\
6 \mathrm{MV}\end{array}$ & $\mathrm{Au}$ & 1.9 \\
\hline [95] & Analytical calculation & $x$ & $6 \mathrm{MV}$ & $\mathrm{Au}$ & 100 \\
\hline [96] & PENELOPE & $x$ & $110-500 \mathrm{kV}$ & $\mathrm{Gd}$ & Not Applicable \\
\hline [63] & $\begin{array}{l}\text { MCNP5 } \\
\text { PENELOPE }\end{array}$ & $X$ or $Y$ & $\begin{array}{l}{ }^{103 \mathrm{Pd}} \\
{ }^{125 \mathrm{I}} \\
{ }^{169} \mathrm{Yb} \\
192 \mathrm{Ir} \\
6 \mathrm{MV}\end{array}$ & $\mathrm{Au}$ & $\begin{array}{l}1.9 \\
5 \\
30 \\
100\end{array}$ \\
\hline [97] & GEANT4 & $\mathrm{x}$ & $\begin{array}{l}6 \mathrm{MV} \\
15 \mathrm{MV}\end{array}$ & $\mathrm{Au}$ & 1.9 \\
\hline [58] & GEANT4 & $\mathrm{X}$ & $\begin{array}{l}20-150 \mathrm{keV} \\
160 \mathrm{kV}\end{array}$ & $\mathrm{Au}$ & 1.9 \\
\hline [98] & PENELOPE & X & $110-500 \mathrm{kV}$ & I & Not Applicable \\
\hline [99] & GEANT4 & Electrons & $\begin{array}{l}50 \mathrm{keV} \\
250 \mathrm{keV} \\
1 \mathrm{MeV} \\
4 \mathrm{MeV}\end{array}$ & $\mathrm{Au}$ & $\begin{array}{l}2 \\
50 \\
100\end{array}$ \\
\hline [45] & PENELOPE & $x$ & $\begin{array}{l}200 \mathrm{keV} \\
1 \mathrm{MeV} \\
6 \mathrm{MeV}\end{array}$ & Hf & 50 \\
\hline [100] & Analytical calculation & $\mathrm{x}$ & $80-120 \mathrm{kV}$ & $\mathrm{Au}$ & 1.9 \\
\hline [101] & Analytical calculation & $x$ & $6 \mathrm{MV}$ & $\mathrm{Au}$ & 100 \\
\hline [59] & GEANT4 & $\mathrm{X}$ & $\begin{array}{l}80 \mathrm{kV} \\
6 \mathrm{MV}\end{array}$ & $\mathrm{Au}$ & 400 \\
\hline [102] & PENELOPE & $x$ & $220 \mathrm{kV}$ & $\mathrm{Au}$ & Not Applicable \\
\hline [103] & MCNPX & $X$ or $Y$ & $\begin{array}{l}50-120 \mathrm{keV} \\
{ }^{60} \mathrm{Co} \\
6 \mathrm{MV} \\
18 \mathrm{MV}\end{array}$ & $\mathrm{Au}$ & $\begin{array}{l}30 \\
50 \\
100\end{array}$ \\
\hline [104] & GEANT4 & $\mathrm{x}$ & $6 \mathrm{MV}$ & $\mathrm{Au}$ & $\begin{array}{l}10 \\
100\end{array}$ \\
\hline [105] & $\begin{array}{l}\text { Analytical calculation; } \\
\text { Eclipse } 8.6 \text { ®Varian } \\
\text { Medical Systems, Palo } \\
\text { Alto, CA, USA }\end{array}$ & $\mathrm{x}$ & $6 \mathrm{MV}$ & $\mathrm{Au}$ & 1.9 \\
\hline
\end{tabular}

We divided the performed studies using medical $\mathrm{X}$-rays into two categories: the first one corresponds to low and medium energies, i.e. comprised between 1 $\mathrm{kV}$ and $1 \mathrm{MV}$ and the other one corresponds to high energies (i.e. 1 to $25 \mathrm{MV}$ ). When achievable, we measured the DMF in papers that contain survival curves to quantify the radiosensitizing effect of NPs. The "biological effect" was defined as the $\mathrm{SF}_{2}$ without NPs (Fig. 2).

A plot of the calculated DMF values versus beam energy is illustrated on figure 3 . Due to the multitude of irradiations settings and environments between experiments, the inter-study comparison of the DMF should be considered with care. Moreover, in some studies, the energy is not the only parameter that varied. Therefore, in order to analyze the source en- ergy parameter only, we have decided to focus on the analysis of papers where the energy was the only variable (Fig. 3). Rahman et al. [49] reported high dose enhancement $(\mathrm{DMF} \leq 0.1)$ at 80 and $150 \mathrm{kV}$ in the same study. Survival curves were obtained using a colorimetric method. It seems that in the presence of NPs, curves do not follow the LQ model anymore ( $a$ $\rightarrow 0$ when the concentration increases). The authors concluded that their results gave an indication of some energy dependence because the source was the only parameter that was changed. Brun et al. [40] assessed the effect of 6 combinations energy/filtration. They could not clearly observe an energy dependence but did not directly measure the cell survival. Their conclusions were based on a plot of the dose enhancement factor versus the effective X-ray energy but 
the enhancement factor was linked to the loss of supercoiled DNA. In another study, Brun et al. [50] evaluated the enhancement of $X$-ray-induced degradations of human centrin 2 proteins (Hscen2). Centrins are small acidic proteins, highly conserved in eukaryotes, from algae and yeast to humans. They demonstrated that X-ray-induced degradations could not lead to explicit energy dependence. However, one could regret that non-standard biological assays were used in these studies. Recently, Rahman et al. [51] observed the influence of the energy of synchrotron-based mono-energetic photon beams (from 30 to $100 \mathrm{keV}$ ) and found out that the optimal energy was $40 \mathrm{keV}$. However, no correlation was made between the source energy and the in-vitro radiosensitization by NPs.

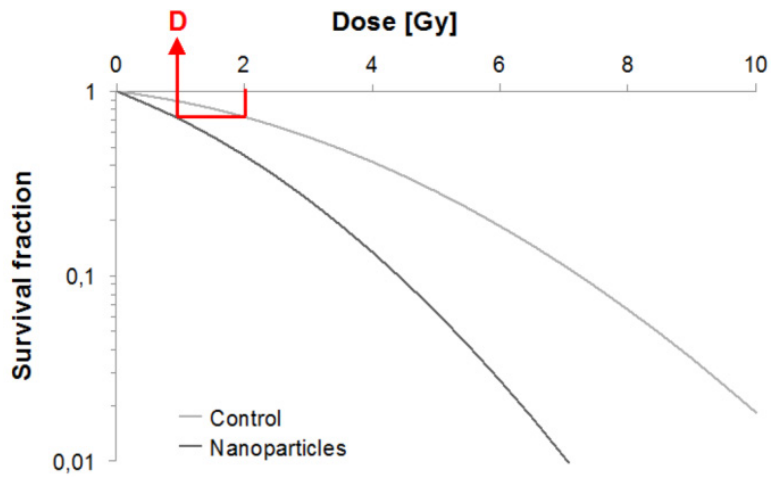

Figure 2. Survival curve example. Illustration of our DMF assessment strategy.

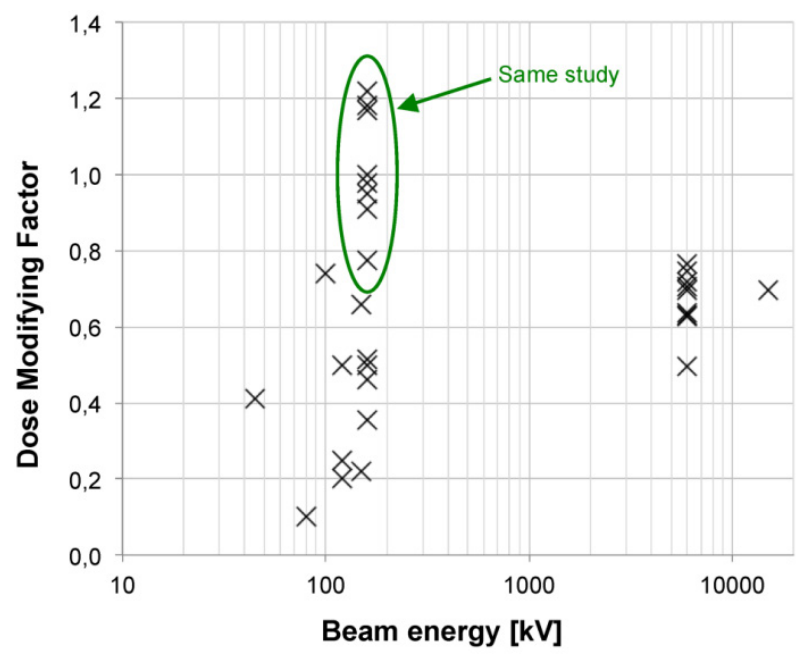

Figure 3. Plot of the calculated DMF values from publications versus beam energy. For energies up to $200 \mathrm{kV}$, we identified 21 publications dealing with in vitro, 2 in vivo and 2 with both in vitro and in vivo experiments during the period 2008-2014. In the range from $200 \mathrm{kV}$ to $1 \mathrm{MV}, 3$ in vitro publications were studied. Upon in vitro experiments, the DMF varies from 0.1 to 1.2. Lower values (which are representative of a high radiosensitization) were observed for lower energies. Concerning high-energy beams, 13 publications were analyzed for in vitro, 1 for in vivo experiments and 1 for both; 1 used a $4 \mathrm{MV}$ beam, 13 a $6 \mathrm{MV}, 1$ a $10 \mathrm{MV}$ and 1 a $15 \mathrm{MV}$. Upon in vitro experiments, the DMF varies from 0.7 to 0.8 for passive GNP, 0.5 for PEG-coated GNP and 0.6 for a Photofrin $\AA$ and quantum dots combination.
Two papers [20,52] demonstrated a noteworthy influence of the energy on the radiosensitizing effect of NPs in SK-OV-3 (105 kV, $220 \mathrm{kV}, 6 \mathrm{MV})$ and MDA-MB-231 (160 kV, 6 MV and 15 MV) cell lines. Concerning the results published by Jain et al. we measured, at $160 \mathrm{kV}$, DMF values of $0.499,1.180$ and 0.776 for MDA-MB-231, DU145 and L132 cell lines respectively. Thus, the cell line parameter seems highly influent. However, for the $6 \mathrm{MV}$ beam, we measured DMFs of $0.695,0.718$ and 0.706 for the 3 cell lines respectively. The DMF measured for MDA-MB-231 after a 15 MV irradiation is 0.695. Surprisingly, at high energies, results do not depend on the cell lines anymore, pointing out that $\mathrm{kV}$ irradiations are more subject to additional variations than MV ones.

As results DMF are, to some extent, disparate for low and medium energy X-rays, they are interestingly similar for high energies (6 MV in particular). This may be due to a noteworthy diversity of low- and medium-energy spectra. Indeed the later beams differ widely from one another for the following reasons (not exhaustive list): large number of tube manufacturers, anode materials, filters, etc and this is certainly a major drawback for the comparison of studies. On the contrary, clinical MV spectra are remarkably similar which makes them more suited for comparisons.

Based on in vitro and in vivo studies published during 2008-2014, we found that there are evidences that the energy of the X-rays source has a major influence on the radiosensitizing power of NPs. We notably noticed that $6 \mathrm{MV}$ irradiations resulted in a DMF close to 0.65 with a low variability even for different NPs designs or cell types. For example, applying a DMF of 0.65 to clinical situations means fractions of 2 Gy could be replaced by 1.3 Gy fractions with the same biological effect on tumors that contain NPs. It could be an important benefit for the patient with less side effects and a better treatment tolerance. Working at $6 \mathrm{MV}$, besides facilitating the comparisons of NPs, would allow easier transitions to clinics where high-energy X-rays are the standards. Nevertheless, as high-energy medical linear accelerators are not easily accessible, a standardization of low-energy irradiation protocols should be proposed to evaluate the radiosensitizing power of NPs in laboratory.

\section{Irradiation setup}

The irradiation methodology may drastically influence the studies results and only few authors have detailed this point. The irradiation should be reproducible, repeatable and close to the clinical situations. It is therefore recommended to comply with the following propositions. The absorbed dose should be correctly calculated: cells/tissues/tumor should be at 
the electronic equilibrium $(\approx$ surrounded by sufficient water equivalent medium). If possible, cells or animal models should be surrounded with water equivalent materials that could bring scattered photons of lower energy (which interacts by photoelectric effect).

The energy held by the scattered photon is related to the energy of the incident photon [53]. Therefore backscattered photons, which carry less energy, are interesting for X-rays-NPs interactions purposes. Then the cells/tissues/tumor should be located in a low dose gradient: after the depth of the maximum dose and inside the beam, off the penumbra region. Sufficient medium should be placed after the cells/tissues/tumor in order to generate enough scattered photons (Compton effect). Finally, cells/tissue/tumor should be at a clinical distance from the source (e.g. $100 \mathrm{~cm}$ for a high-energy medical accelerator). Advices from a medical physicist could be of great use. The figure 4 illustrates an example of an irradiation scheme for a $6 \mathrm{MV}$ accelerator treating a cell well plate.

For precise inter-study comparisons, the irradiation methodology should be the same with similar beam energy spectra. That is why high-energy beams (e.g. $6 \mathrm{MV}$ ) are well suited for that purpose.

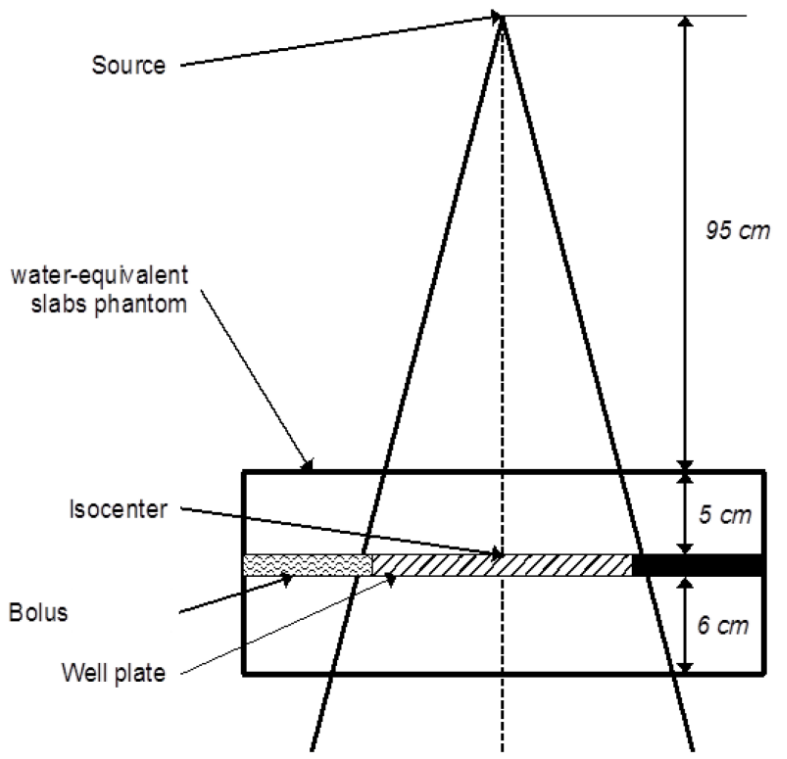

Figure 4. Example of a standard irradiation setup for a $6 \mathrm{MV}$ irradiation of a cell-well plate placed at the linear accelerator's isocenter under $5 \mathrm{~cm}$ of water-equivalent slabs.

\section{Influence of nanoparticles design on the radiosensitization}

NPs usually have a simple structure composed of a core, a shell and a surface [54]. In the case of radiosensitizing NPs, the core is usually made of high- $Z$ materials such as silver, lanthanides and most extensively of gold, in order to exploit the increased photon absorption. The shell, which is chemically or physically bound to the core, acts as a base on which surface molecules (which sometimes include active agents) are anchored or bound with or without spacers. However, the high Z-elements can also be chelated by ligands present at the surface or inside the nanoparticle. The surface molecules usually consist of site-, tissue-, cell- and/or receptor-specific molecules (targeting units). In the following paragraphs we will review the influence of the NPs design on: (i) interactions between X-rays and NPs, (ii) the ROS generation upon irradiation and (iii) the biodistribution of NPs.

\section{$X$-rays -nanoparticles interactions}

Theoretical principles of X-rays interactions with NP have already been described [33]. X-ray interactions with matter happen mostly at low energy where the photoelectric effect is dominant (Fig. 5). The photoelectric effect occurs when the incident X-ray photon is absorbed by the atom, resulting in the ejection of an electron. This effect is prevailing until the photon energy reaches a medium energy (e.g. $500 \mathrm{keV}$ for $\mathrm{Au}$ ) with a cross-section varying with $\mathrm{Z}^{4}$ or $\mathrm{Z}^{5}$ depending on the material and is enhanced by an increased absorption by electron shells (K, L, M, etc.) at low energies. As the atom is left in an ionized state, a characteristic X-ray or an Auger-electron emission follows the ejection of a photoelectron. That is why the radiosensitizing NPs are based on high-Z materials. More theoretical proofs can be found in the literature $[6,55]$. The Auger effect especially concerns low-Z atoms [56] and therefore would not be a major contributor to the dose deposited in the presence of high-Z NPs. Indeed, it is dominant for $Z<15$ but almost equal to 0 for $Z>60$ [57].

For medium- or high-energy beams (always poly-energetic in clinical routine), the low-energy component of the spectrum will interact with matter by photoelectric effect and the medium- and high-energy components are more likely to interact by Compton effect. Compton effect occurs when the incident X-ray ejects an electron and a photon is scattered from the atom. This effect does not depend on the $\mathrm{Z}$ of the targets. The scattered photon, depending on its energy, will trigger either photoelectric or Compton effects.

Compton, Photo- or Auger-electrons can induce the emission of secondary electrons (also called delta rays) that are believed to be responsible for the majority of cells damages. One should notice that for very low energies photons, the ejected photoelectron might not carry a sufficient energy to cause subsequent ionizations. Opposite information about the dose deposited by Auger or photo-electrons in the vicinity of the NPs have been published in the litera- 
ture. McMahon et al. found that the contribution of Auger electrons was dominant [58] and Douglass et al. claimed that the Auger electrons contribution was insignificant [59] even though they were using the same simulation code (Geant4). Some authors described an auto-absorption phenomenon that can be amplified by the size of the NPs and the presence of other high-Z atoms in its vicinity (e.g. a cluster of NPs)
[58]. Low-energy secondary species would be the first to be absorbed. Therefore the design of the NPs is of utmost importance concerning the radiation therapy enhancement; high- $Z$ components can increase the number of secondary species because of a $Z^{5}$ dependence of the photoelectric effect and bigger NPs or clusters tends to favorite the auto-absorption of low energy electrons.

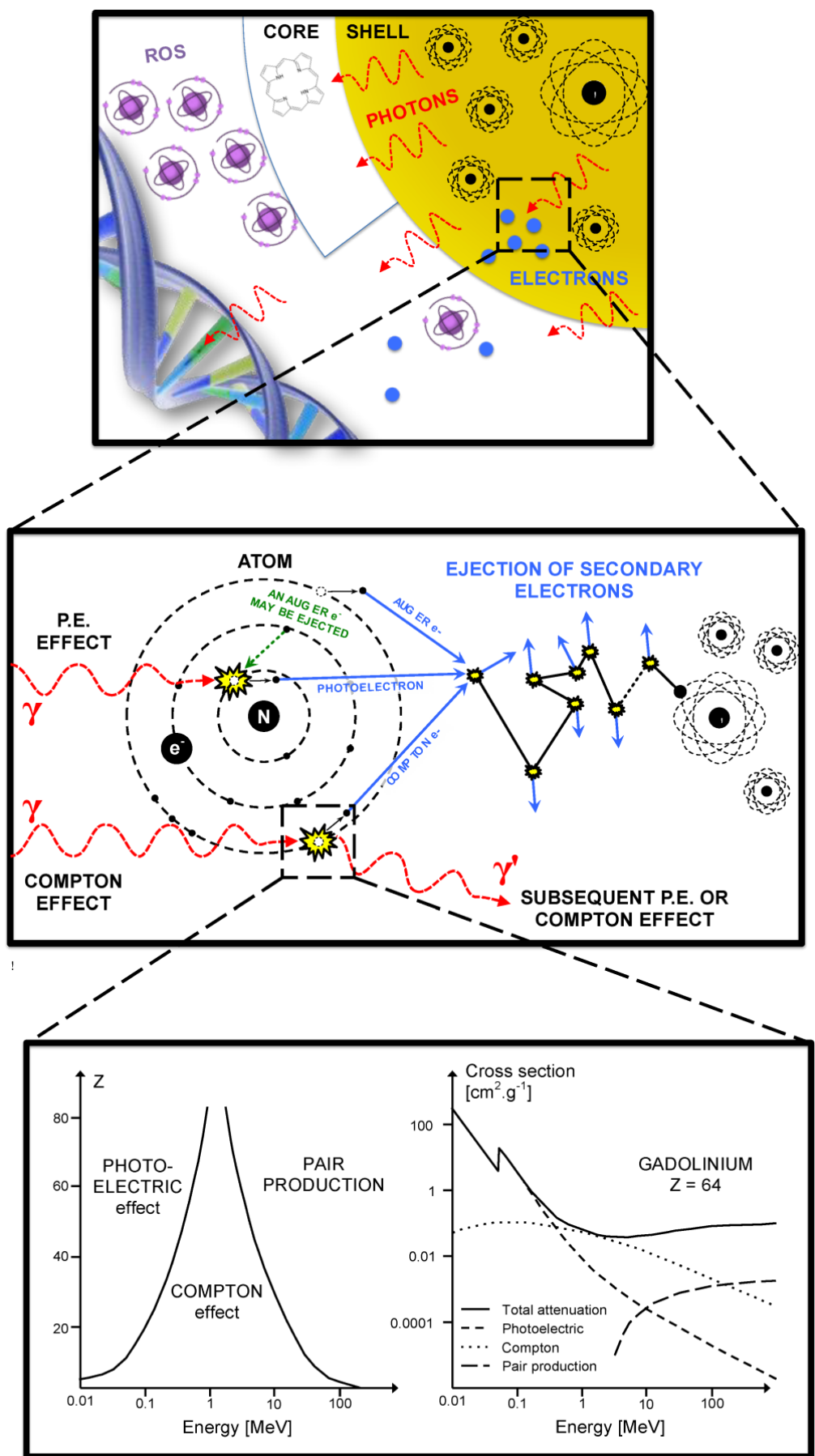

Figure 5. Interactions of X-rays with NPs result directly or indirectly in the production of secondary species: photons, electrons and later ROS. Secondary photons or electrons are mostly generated either by photoelectric or Compton effect. The photoelectric effect interaction probability varies with $Z^{4}$ or $Z^{5}$ and dominant until the incident photon energy reaches $\approx 500 \mathrm{keV}$. 
Heavy metal-based NPs have also been suggested as effective tumor-targeting theranostic agents with dual functions: efficient targeted system for tumor imaging and irradiation dose amplifier for radiotherapy under the guidance of computed tomography imaging [60]. Guided by tumor-targeted X-ray computed tomography imaging, their radiosensitizing effect was investigated using a clinical megavoltage photon beam. In this innovative study, BaYbF5: $2 \%$ Er3 + NPs could be excited by near-infrared laser and emit upconversion luminescence with greatly suppressed auto fluorescence, photo damage and toxicity, which could be ideal for cell or even tissue tracking.

\section{ROS generation upon X-rays}

The mechanisms involved in the ROS generation upon X-rays irradiation in the presence of NPs differ depending on the composition, size, and potential of these NPs. Thereby, Misawa et al., using two kinds of fluorescent probe APF and DHE, compared the ROS production when GNP, from 5 to $250 \mathrm{~nm}$, were subjected to X-rays irradiation and UV light in water [24]. GNP-induced enhancement of $\mathrm{OH}$ and $\mathrm{O}_{2} \cdot-$ generation was confirmed. Moreover, the authors demonstrated that smaller diameter GNP with larger surface area showed a greater yield of ROS. The increase in ROS generation was also corroborated by recently published results of Klein and al, which illustrates the in vitro formation of ROS in SuperParamagnetic Iron Oxide Nanoparticles (SPIONs) loaded MCF-7 cells exposed to X-rays. In particular, they demonstrated that citrate-coated SPIONs may function as excellent radiosensitizers upon enhancing the impact of X-rays on the ROS generation for about $240 \%$ when compared with X-ray treated cells without internalized SPIONs. The ROS production in iron oxide NP loaded cells was explained to originate from both, the release of iron ions and the catalytically active surfaces of silica NPs with an oxidation of $\mathrm{SiO}_{2}$ following irradiation [23-25]. Interestingly, a link was evidenced between the intracellular localization of SPIONs, and the ROS generation; functionalization with an amine function of silica NPs can significantly increase the
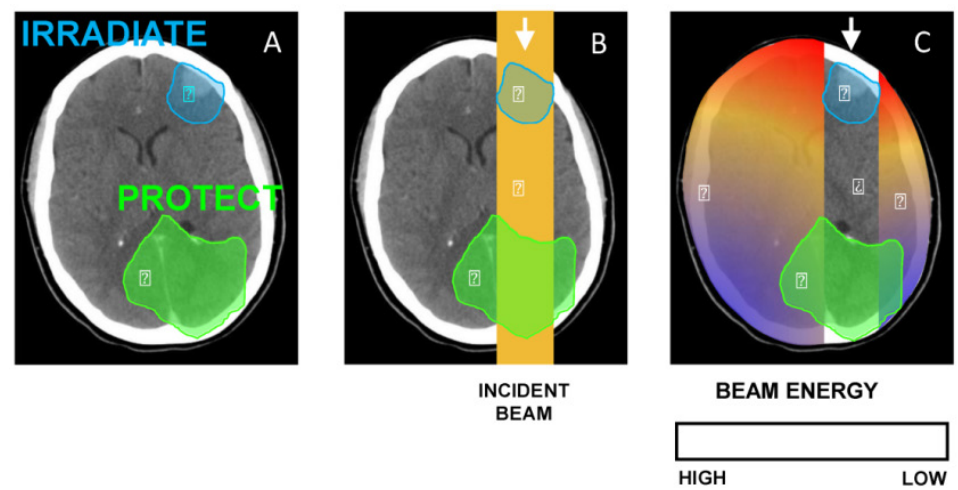

ROS production due to their positive surface charge, which facilitates NPs accumulation in the membranes of the endoplasmic reticulum, vesicles and especially mitochondria [61]. SPIONs presence in the membranes also induced a membrane lipid peroxidation, improving the radiosensitizing effect [61].

\section{Influence of nanoparticles design on tumor selectivity, cellular uptake, intracellular local- ization and biodistribution}

As organs at risks may be at the vicinity of the tumor and given that there is some evidence of an energy dependence of the radiosensitization by NPs, this observation has to be taken into consideration when prescribing NPs (Fig. 6). Therefore, it is of utmost importance that radiosensitizing NPs concentrate in the tumor and not in the healthy organs at its vicinity. That is why it has been suggested that GNP-based radiosensitizers should have targeting moieties (e.g. glucose, antibodies) to improve NP uptake by tumor cells. For example, Chattopadhyay et al. demonstrated that trastuzumab-conjugated GNPs were well-internalized into HER-2 overexpressing SK-BR-3 breast cancer, while non-targeted NPs had little or no internalization in these cells, and trastuzumab-conjugated GNP have led to 5 times more DNA double strand breaks than the non-targeted GNP. It should also be noticed that the energy spectrum of radiation therapy beams always depends on the clinical setting (depth, field size, in-field localization of NPs, etc.). Scarboro et al. calculated $6 \mathrm{MV}$ energy spectra variations with treatment parameters [62]. They showed that when the depth along the central axis increased, the low-energy contribution of the spectrum increased and the high-energy part decreased. For instance, for a $10 \mathrm{~cm} \mathrm{x}$ $10 \mathrm{~cm}$ field, at a depth of $10.0 \mathrm{~cm}$ the flux of particles which carry an energy of $100 \mathrm{keV}$ is two times more important than at a depth of $1.6 \mathrm{~cm}$. Therefore, the radiosensitizing effect of NPs may be slightly more important for deep tumors. They also noticed that off axis spectra contained dramatically more low energy components that central axis ones.

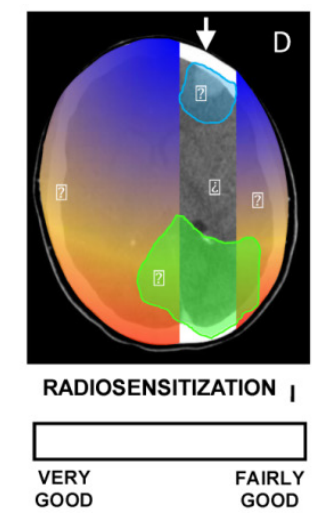

Figure 6. (A) Illustration of a clinical scenario where a volume (blue) has to be irradiated while a part of an organ (green) has to be protected. (B) A simple anterior beam is irradiating the blue volume. (C) The beam energy is maximum in the irradiation field and is reduced out of the field. (D) Given that the interaction probability is higher for low-energy photons, the radiosensitization in presence of NPs should be higher out of the irradiation field. In this case, the green volume that has to be protected would be in the most radiosenzitized area. 
At a cellular level, several studies aimed at estimating the diffusion abilities of secondary species induced in case of interactions between X-rays and $\mathrm{NP}$ and most of authors have concluded that the path of secondary electrons is very limited, from a few tens of nanometers to a few micrometers. For example, Chattopadhyay et al. using a $100 \mathrm{kVp}$ X-ray beam and GNPs, reported that $99 \%$ of the Auger electrons were stopped before $100 \mathrm{~nm}$, because of their low average energy and a very short penetration range [42,63]. Meesungnoen et al., for their part, have described a penetration range shorter than $20 \mu \mathrm{m}$ for photoelectrons with an average energy of about $43 \mathrm{keV}$ [64]. Given that the cell size was about $10-20 \mu \mathrm{m}$, these works suggest that lethal effects resulting from $X$-rays and NP interactions could only be obtained if NPs are localized into the cell. Hence, the internalization of NP into tumor cells is a pre-requisite. Cellular uptake of NPs is highly dependent on the design of the nano-object and numerous studies have demonstrated that modifications of the physicochemical properties of the NP have great consequences on the cellular entry and biological processes [65]. In a recent work, Rima et al. assessed the cellular internalization mechanisms for sub-5 nm gadolinium-based NPs and evidenced both passive diffusion for single particles and macropinocytosis in case of agglomerates [34]. Herein, significant radiosensitization was only found with NPs clusters.

Besides the impact on cellular uptake, NP design also determines their intracellular localization, which in turn exerts a critical impact on the induced radiosensitization. In particular, the functionalization of the NPs plays a central role in the redirection of the particle to specific cell subcompartments. For instance, Kong et $a l$. demonstrated that their GNPs were mostly bound to the cell membrane, while thioglucose-GNPs were distributed in the cytoplasm, leading to a higher decrease in cell survival after X-rays irradiation [35]. However, in a recent study [66], a sub-50 nm nuclear-targeting rattle-structured upconversion core/mesoporous silica nanotheranostic system was designed to directly deliver radiosensitizing drug Mitomycin $\mathrm{C}$ into the nucleus for greatly enhanced damaging of the DNA with the assistance of X-ray irradiation. More importantly, the authors develop a new theranostic technique of "intranuclear radiosensitization", meaning that the radiosensitizing drug molecules released into the nucleoplasm may not only efficiently break down the intranuclear DNA, but also effectively enhance the radiotherapy efficacy due to the intranuclear chemodrug-sensitized radiation enhancement effects Moreover, in vitro significant radiosensitization has been noted for GNPs localized far from the cell nucleus [49]. Consistently, according to the recent literature in this field, it seems that the relative distance from the DNA is not a crucial factor [52, 67].

Concerning in vivo applications of NP-based radiosensitization, the first priority concerns the NP selectivity for tumor tissue to avoid any radiosensitization of adjacent normal tissue. To circumvent this difficulty, intratumoral injection was sometimes preferred and used $[42,45]$. For systemic delivery, the engineering of NPs on the size, shape, physicochemical characteristics and targeting moieties is critical, given that these parameters strongly affect the circulation time of the NPs, their biodistribution and their availability for effective therapy [68]. As described by Dufort et al., after intra-venous injection, accumulation of GNPs in the tumor tissue could be achieved passively by relying on the increased permeation and retention of the leaky vasculature of tumors (EPR effect) [65]. Nevertheless, the tumor-to-normal tissue NP ratios need to be improved in further preclinical trials. Notably, in preclinical in vivo studies, few experiments were conducted to optimize the time between NPs administration and irradiation, while this point appears to be critical. However, NPs have been suggested as theranostic agents for tumor imaging and irradiation dose amplifier for radiotherapy under the guidance of computed tomography imaging [60].

\section{Future applications: $e . g$. photodynam- ic-therapy combined with high-Z radio- sensitizers}

PDT is based on the concept that certain PhotoSensitizers (PS) can be localized in neoplastic tissue, and can subsequently be activated with the appropriate wavelength of light to generate active molecular species such as free radicals and singlet oxygen $\left({ }^{1} \mathrm{O}_{2}\right)$ that are toxic to tumors. The limited penetration range of light makes this therapy most appropriate for small or superficial lesions. In order to treat deep lesions, it may be possible to use X-rays as excitation source instead of light. With this novel therapeutic approach, the light penetration problem can be overcome and activation of the photosensitizer within tumors would be performed using ionizing radiation. This new modality will allow treatment of deep tumors using lower radiation dose than conventional radiotherapy.

Chen $\mathrm{W}$ and Zhang J described for the first time the potential of NPs to enable simultaneous radiation and photodynamic treatment in 2006 [5] and in a review in 2008 [69]. They obtained an US patent in 2007 for luminescent NPs with attached PSs such as porphyrins used as a new type of agents for PDT. Upon exposure to ionizing radiation, light would be emitted from the NPs to activate the PS; as a consequence, ${ }^{1} \mathrm{O}_{2}$ 
would be produced to increase the killing of cancer cells by ionizing radiation. No external light would be necessary to activate the PS within the tumor. Chen and Zhang described the synthesis of $\mathrm{LaF}_{3}: \mathrm{Tb}^{3+}$-meso-tetra(4-carboxyphenyl)porphine (MTCP) NP conjugated to folic acid and investigated the energy transfer as well as the formation of ${ }^{1} \mathrm{O}_{2}$ following X-ray irradiation [70]. They proved that upon X-ray irradiation, the porphyrin alone is a radiosensitizer but the effect is enhanced when MTCP is coupled to $\mathrm{LaF}_{3}: \mathrm{Tb}^{3+} \mathrm{NPs}$ targeted or not with folic acid. The average energy transfer rate in the MTCP conjugates is $56.7 \%$. The same team realized also ZnO-MTAP (meso-(o-amino-phenyl porphine)conjugate in which the energy transfer is around $89 \%$ [70].

In 2009, Morgan et al. [71] tried to calculate the physical parameters required for nanoscintillators to deliver cytotoxic levels of ${ }^{1} \mathrm{O}_{2}$ at therapeutic radiation doses drawing on the published literature from several disparate fields. It appears that the light yield of scintillators, the efficiency of energy transfer to the PS and the cellular uptake of the NPs all need to be fairly well optimized to observe a cytotoxic effect. To calculate the required light yield for the NPs to have a PDT effect (formation of $5.6 \times 10^{7}$ of ${ }^{1} \mathrm{O}_{2}$ ) at therapeutic radiation doses, they assumed a non-clinical single-fraction radiation dose of $60 \mathrm{~Gy}, \Phi_{\mathrm{FRET}}=0.75, \Phi_{\Delta}=$ 0.89 and that NPs occupy a $5 \%$ volume fraction in the tissue. They estimated that the efficacy of the combination therapy would likely be restricted to X-ray energies below $300 \mathrm{keV}$.

Scaffidi et al. in 2011 [72], described $\mathrm{Y}_{2} \mathrm{O}_{3}$ nanoscintillator, a fragment of HIV-1 TAT peptide and psoralen. The authors used commercially available 12 nm diameter cubic-phase $\mathrm{Y}_{2} \mathrm{O}_{3}$ nanoscintillators on which they coupled TAT or psoralen-TAT. PC-3 human prostate cancer cells were used and they could observe a modest in vitro reduction in cell number after X-ray excitation (2 Gy at 160 or $320 \mathrm{kV}$ ).

Our team published very recently a paper about X-ray-induced ${ }^{1} \mathrm{O}_{2}$ activation with nanoscintillator-coupled porphyrins (Fig. 7) [73]. $\mathrm{Tb}_{2} \mathrm{O}_{3}$ coated with a polysiloxane layer is a biocompatible nanoscintillator that exhibits an appropriate pattern of biodistribution in vivo after injection. The average size of the core-shell NPs grafted with porphyrin is 9.9 $\mathrm{nm}$. Using time-resolved laser spectroscopy and ${ }^{1} \mathrm{O}_{2}$ chemical probes, we demonstrated that after X-ray irradiation of the nano-objects, we could observe the formation of ${ }^{1} \mathrm{O}_{2}$ as well as a decrease of the luminescence of the core and the increase of the fluorescence of the porphyrin, proving the energy transfer between the core and the photosensitizer. By elaborating new NPs, we hope to increase the efficiency and prove the concept in vitro and in vivo.

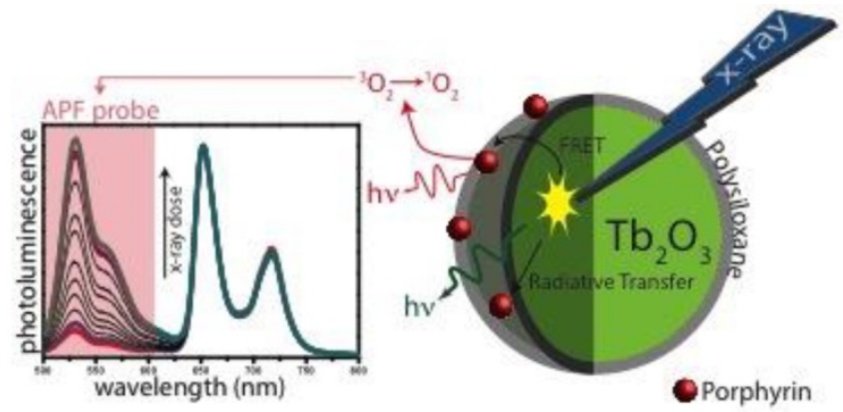

Figure 7. Luminescence of APF probe after X-rays excitation of nanoparticles

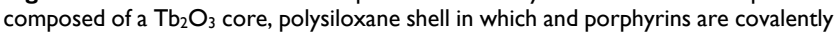
linked.

In 2015, inspired by the complementary advantages of PDT and radiotherapy, Zhang et al. described the integration of a scintillator and a semiconductor as an ionizing-radiation-induced PDT agent, achieving synchronous radiotherapy and depth-insensitive PDT with diminished molecular $\mathrm{O}_{2}$ dependence [74]. These very encouraging results are the basis of new NPs developments. Recent Monte Carlo simulations have also been used to numerically estimate the spatial energy distribution resulting from the interaction between the X-ray photon and the NP, leading to a photodynamic and radiosensitization efficiencies. These simulations demonstrated that a significant fraction of energy is deposited within the NPs despite a primary interaction occurring in the surrounding media [75].

\section{Conclusion and future perspectives}

We have reviewed parameters that influence the radiosensitizing power of NPs: the biological evaluation methodology, the X-rays energy, the irradiation setup, the X-rays-NPs interaction, the ROS generation and the biodistribution of the NPs. A numerical evaluation was performed to assess the impact of the $X$-rays energy spectrum on the cell survival in presence of NPs. After the analysis of 64 papers from the literature, we noted that a large number of prospective studies have been carried out on the NPs-enhanced radiation therapy. However, only a few papers were comparable because the experimental settings were different, thus leading to uncertainty as to whether some parameters were influent or not, indicating that more investigations and standardizations are needed to converge towards a conclusion. Nevertheless, the present review strengthens the approach of using NPs to improve radiation therapy. Another parameter that has just been evaluated by Jain et al. is the influence of the oxygen conditions [76]. They showed that the radiosensibilization power of GNP is lower in hypoxic conditions. The knowledge 
of these critical parameters could help investigators to design and evaluate new NPs in a more normalized approach which will be necessary for further translation to clinical applications.

Due attention needs to be paid to the recent emergence of very promising reports about the in vitro/in vivo synergetic therapy based on radiosensitization for instance, (i) an enhanced radiotherapy and photothermal ablation under the potential trimodal imaging guidance [22], or a simultaneous dual-mode imaging and localized therapy via synergetic chemo-/radiotherapy [77] or a synergetic chemo-/radio-/PDT and simultaneous magnetic/ upconversion luminescent bimodal imaging [78].

Last but not least, in silico tests could be suggested to screen different nanoparticle designs as a first step to identify the most promising nano-objects. Indeed, a numerical model-based design could allow for quick screening of a large number of architectural configurations and finally identify the most promising formulations to enhance the dose deposition.

\section{Abbreviations}

ADPA, anthracenedipropionic acid; AIEA, International Atomic Energy Agency; APF, aminophenyl fluorescein; CFU, colony forming unit; DCFH, Dichlorodihydrofluorescein; DHE, dihydroethidium; DHF, dichlorofluorescein; DMF, Dose Modifying Factor; DNA, deoxyribonucleic acid; EPR, enhanced permeability and retention; FFA, furfuryl alcohol; GNP, gold-based nanoparticle; HIS, histidine; LQ, linear-quadratic; IAEA, International Atomic Energy Agency; ICRP, International Commission on Radiological Protection; ICRU, International Commission on Radiation Units \& Measurement; MRI, magnetic resonance imaging; NER, Nanoparticle-mediated Enhancement Ratio; NP, nanoparticle; PDT, photodynamic therapy; PS, photosensitizer; RBE, Relative Biological Effectiveness; ROS, reactive oxygen species; $\mathrm{SF} 2$, survival fraction at $2 \mathrm{~Gy} ;{ }^{1} \mathrm{O}_{2}$, singlet oxygen; SOSG, singlet oxygen sensor green; SPION: superparamagnetic iron oxide nanoparticles.

\section{Acknowledgement}

This work was supported by the research funds of the ANR P2N ANR-10-NANO-0009 PDTX and INCa "PDTX-Nano", the French Ligue Nationale Contre le Cancer and the French INCa (Institut National du Cancer) project 2011-130 entitled "PDTX-Nano".

The authors would like to thank Wael Rima for his advices and the review of the English language of this manuscript.

\section{Competing Interests}

The authors have declared that no competing interest exists.

\section{References}

1. Wagner V, Dullaart A, Bock AK, Zweck A. The emerging nanomedicine landscape. Nat Biotechnol. 2006; 24: 1211-7.

2. Thiesen B, Jordan A. Clinical applications of magnetic nanoparticles for hyperthermia. Int J Hyperth. 2008; 24: 467-74.

3. Jordan A, Scholz R, Maier-Hauff K, van Landeghem FK, Waldoefner N, Teichgraeber $\mathrm{U}$, et al. The effect of thermotherapy using magnetic nanoparticles on rat malignant glioma. J Neurooncol. 2006; 78: 7-14.

4. Starkewolf ZB, Miyachi L, Wong J, Guo T. X-ray triggered release of doxorubicin from nanoparticle drug carriers for cancer therapy. Chem Commun. 2013; 49: 2545-7.

5. Chen $\mathrm{W}$, Zhang J. Using nanoparticles to enable simultaneous radiation and photodynamic therapies for cancer treatment. J Nanosci Nanotechnol. 2006; 6: 1159-66.

6. Hainfeld JF, Dilmanian FA, Slatkin DN, Smilowitz HM. Radiotherapy enhancement with gold nanoparticles. J Pharm Pharmacol. 2008; 60: 977-85.

7. Townley HE, Kim J, Dobson PJ. In vivo demonstration of enhanced radiotherapy using rare earth doped titania nanoparticles. Nanoscale. 2012; 4: 5043-50

8. Mirjolet C, Papa AL, Crehange G, Raguin O, Seignez C, Paul C, et al. The radiosensitization effect of titanate nanotubes as a new tool in radiation therapy for glioblastoma: a proof-of-concept. Radiother Oncol. 2013; 108: 136-42.

9. Takahashi J, Misawa M. Analysis of Potential Radiosensitizing Materials for X-Ray-Induced Photodynamic Therapy. Nanobiotechnol. 2007; 3: 116-26.

10. Yang W, Read PW, Mi J, Baisden JM, Reardon KA, Larner JM, et al. Semiconductor nanoparticles as energy mediators for photosensitizer-enhanced radiotherapy. Int J Radiat Oncol Biol Phys. 2008; 72: $633-5$

11. Le Duc G, Miladi I, Alric C, Mowat P, Brauer-Krisch E, Bouchet A, et al. Toward an image-guided microbeam radiation therapy using gadolinium-based nanoparticles. ACS nano. 2011; 5: 9566-74.

12. Liu $P$, Huang $Z$, Chen $Z, X u R, W u ~ H$, Zang F, et al. Silver nanoparticles: a novel radiation sensitizer for glioma? Nanoscale. 2013; 5: 11829-36.

13. Coulter JA, Jain S, Butterworth KT, Taggart LE, Dickson GR, McMahon SJ, et al. Cell type-dependent uptake, localization, and cytotoxicity of $1.9 \mathrm{~nm}$ gold nanoparticles. Int J Nanomedicine. 2012; 7: 2673-85.

14. Franken NA, Rodermond HM, Stap J, Haveman J, van Bree C. Clonogenic assay of cells in vitro. Nat Protoc. 2006; 1: 2315-9.

15. Kirkpatrick JP, Brenner DJ, Orton CG. The linear-quadratic model is inappropriate to model high dose per fraction effects in radiosurgery. Med Phys. 2009; 36: 3381-4

16. Agency IAE. Relative Biological Effectiveness in Ion Beam Therapy. International Atomic Energy Agency; 2008.

17. Valentin J. Relative Biological Effectiveness (RBE), Quality Factor (Q), and Radiation Weighting Factor (Wr). International Commission on Radiological Protection; 2003

18. ICoR Units Measurements. Quantitative Concepts and Dosimetry in Radiobiology. International Commission on Radiation Units and Measurements; 1979

19. Podgoršak EB, Agency IAE. Radiation oncology physics: a handbook for teachers and students. International Atomic Energy Agency; 2005.

20. Jain S, Coulter JA, Hounsell AR, Butterworth KT, McMahon SJ, Hyland WB, et al. Cell-specific radiosensitization by gold nanoparticles at megavoltage radiation energies. Int J Radiat Oncol Biol Phys. 2011; 79: 531-9.

21. Sim L, Fielding A, English M, Waclawik E, Rockstroh A, Soekmadji C, et al. Enhancement of biological effectiveness of radiotherapy treatments of prostate cancer cells in vitro using gold nanoparticles. Coogee Beach, Sydney, NSW: 2011 International Nanomedicine Conference. 2011.

22. Xiao Q, Zheng X, Bu W, Ge W, Zhang S, Chen F, et al. A core/satellite multifunctional nanotheranostic for in vivo imaging and tumor eradication by radiation/photothermal synergistic therapy. J Am Chem Soc. 2013; 135: 13041-8

23. Klein S, Sommer A, Distel LV, Neuhuber W, Kryschi C. Superparamagnetic iron oxide nanoparticles as radiosensitizer via enhanced reactive oxygen species formation. Biochem Biophys Res Commun. 2012; 425: 393-7.

24. Misawa M, Takahashi J. Generation of reactive oxygen species induced by gold nanoparticles under x-ray and UV Irradiations. Nanomedicine. 2011; 7: 604-14.

25. David Gara P, Garabano N, Llansola Portoles M, Moreno MS, Dodat D, Casas $\mathrm{O}$, et al. ROS enhancement by silicon nanoparticles in X-ray irradiated aqueous suspensions and in glioma C6 cells. J Nanopart Res. 2012; 14: 1-13.

26. Townley HE, Rapa E, Wakefield G, Dobson PJ. Nanoparticle augmented radiation treatment decreases cancer cell proliferation. Nanomedicine. 2012; 8: 526-36. 
27. Wang L, Yang W, Read P, Larner J, Sheng K. Tumor cell apoptosis induced by nanoparticle conjugate in combination with radiation therapy. Nanotechnology. 2010; 21: 475103.

28. Geng F, Song K, Xing JZ, Yuan C, Yan S, Yang Q, et al. Thio-glucose bound gold nanoparticles enhance radio-cytotoxic targeting of ovarian cancer. Nanotechnology. 2011; 22: 285101.

29. Cui FB, Li RT, Liu Q, Wu PY, Hu WJ, Yue GF, et al. Enhancement of radiotherapy efficacy by docetaxel-loaded gelatinase-stimuli PEG-Pep-PCL nanoparticles in gastric cancer. Cancer Lett. 2014; 346: 53-62.

30. Chang M-Y, Shiau A-L, Chen Y-H, Chang C-J, Chen HHW, Wu C-L. Increased apoptotic potential and dose-enhancing effect of gold nanoparticles in combination with single-dose clinical electron beams on tumor-bearing mice. Cancer Sci. 2008; 99: 1479-84.

31. Roa W, Zhang X, Guo L, Shaw A, Hu X, Xiong Y, et al. Gold nanoparticle sensitize radiotherapy of prostate cancer cells by regulation of the cell cycle. Nanotechnology. 2009; 20: 375101.

32. Liu CJ, Wang $\mathrm{CH}$, Chen $\mathrm{ST}$, Chen $\mathrm{HH}$, Leng $\mathrm{WH}$, Chien $\mathrm{CC}$, et al. Enhancement of cell radiation sensitivity by pegylated gold nanoparticles. Phys Med Biol. 2010; 55: 931-45.

33. Butterworth KT, McMahon SJ, Currell FJ, Prise KM. Physical basis and biological mechanisms of gold nanoparticle radiosensitization. Nanoscale. 2012; 4: 4830-8.

34. Rima W, Sancey L, Aloy MT, Armandy E, Alcantara GB, Epicier T, et al. Internalization pathways into cancer cells of gadolinium-based radiosensitizing nanoparticles. Biomaterials. 2013; 34: 181-95.

35. Kong T, Zeng J, Wang X, Yang X, Yang J, McQuarrie S, et al. Enhancement of radiation cytotoxicity in breast-cancer cells by localized attachment of gold nanoparticles. Small. 2008; 4: 1537-43.

36. Khoshgard K, Hashemi B, Arbabi A, Rasaee MJ, Soleimani M. Radiosensitization effect of folate-conjugated gold nanoparticles on HeLa cancer cells under orthovoltage superficial radiotherapy techniques. Phys Med Biol. 2014; 59: 2249-63.

37. Mowat $\mathrm{P}$, Mignot A, Rima W, Lux F, Tillement $\mathrm{O}$, Roulin $\mathrm{C}$, et al. In vitro radiosensitizing effects of ultrasmall gadolinium based particles on tumour cells. J Nanosci Nanotechnol. 2011; 11: 7833-9.

38. Zhang XD, Wu D, Shen X, Chen J, Sun YM, Liu PX, et al. Size-dependent radiosensitization of $\mathrm{PEG}$-coated gold nanoparticles for cancer radiation therapy. Biomaterials. 2012; 33: 6408-19.

39. Butterworth KT, Wyer JA, Brennan-Fournet M, Latimer CJ, Shah MB, Currell FJ, et al. Variation of strand break yield for plasmid DNA irradiated with high-Z metal nanoparticles. Radiat Res. 2008; 170: 381-7.

40. Brun E, Sanche L, Sicard-Roselli C. Parameters governing gold nanoparticle X-ray radiosensitization of DNA in solution. Colloids and surfaces B, Biointerfaces. 2009; 72: 128-34.

41. Hossain M, Luo Y, Sun Z, Wang C, Zhang M, Fu H, et al. X-ray enabled detection and eradication of circulating tumor cells with nanoparticles. Biosens Bioelectron. 2012; 38: 348-54.

42. Chattopadhyay N, Cai Z, Kwon YL, Lechtman E, Pignol JP, Reilly RM. Molecularly targeted gold nanoparticles enhance the radiation response of breast cancer cells and tumor xenografts to X-radiation. Breast Cancer Res Treat. 2013; 137: 81-91.

43. Ngwa W, Korideck H, Kassis AI, Kumar R, Sridhar S, Makrigiorgos GM, et al. In vitro radiosensitization by gold nanoparticles during continuous low-dose-rate gamma irradiation with I-125 brachytherapy seeds. Nanomedicine. 2013; 9: 25-7.

44. Chattopadhyay N, Fonge H, Cai Z, Scollard D, Lechtman E, Done SJ, et al. Role of antibody-mediated tumor targeting and route of administration in nanoparticle tumor accumulation in vivo. Mol Pharm. 2012; 9: 2168-79.

45. Maggiorella L, Barouch G, Devaux C, Pottier A, Deutsch E, Bourhis J, et al. Nanoscale radiotherapy with hafnium oxide nanoparticles. Future Oncol. 2012; 8: 1167-81.

46. Hainfeld JF, Smilowitz HM, O'Connor MJ, Dilmanian FA, Slatkin DN. Gold nanoparticle imaging and radiotherapy of brain tumors in mice. Nanomedicine. 2013; 8: 1601-9.

47. Jeong SY, Park SJ, Yoon SM, Jung J, Woo HN, Yi SL, et al. Systemic delivery and preclinical evaluation of $\mathrm{Au}$ nanoparticle containing beta-lapachone for radiosensitization. J Control Release. 2009; 139: 239-45.

48. LAB SL, et al. Biological Effectiveness of Low Linear-Energy Transfer Radiation as a Function of Energy. National Council on Radiation Protection \& Measurements; Not released.

49. Rahman $\mathrm{WN}$, Bishara N, Ackerly $\mathrm{T}, \mathrm{He} \mathrm{CF}$, Jackson $\mathrm{P}$, Wong $\mathrm{C}$, et al. Enhancement of radiation effects by gold nanoparticles for superficial radiation therapy. Nanomedicine. 2009; 5: 136-42.

50. Brun E, Duchambon P, Blouquit Y, Keller G, Sanche L, Sicard-Roselli C. Gold nanoparticles enhance the $\mathrm{X}$-ray-induced degradation of human centrin 2 protein. Rad Phys Chem. 2009; 78: 177-83.

51. Rahman WN, Corde S, Yagi N, Abdul Aziz SA, Annabell N, Geso M. Optimal energy for cell radiosensitivity enhancement by gold nanoparticles using synchrotron-based monoenergetic photon beams. Int J Nanomedicine. 2014; 9: 2459-67.

52. Chithrani DB, Jelveh S, Jalali F, van Prooijen M, Allen C, Bristow RG, et al. Gold nanoparticles as radiation sensitizers in cancer therapy. Radiat Res. 2010; 173: 719-28.
53. Mohr PJ, Taylor BN, Newell DB. CODATA recommended values of the fundamental physical constants: 2006a). J Phys Chem Ref Data. 2008; 37: 1187-284.

54. Fukumori $Y$, Ichikawa $H$. Nanoparticles for cancer therapy and diagnosis. Adv Powder Technol. 2006; 17: 1-28.

55. McMahon SJ, Mendenhall MH, Jain S, Currell F. Radiotherapy in the presence of contrast agents: a general figure of merit and its application to gold nanoparticles. Phys Med Biol. 2008; 53: 5635-51.

56. Martin JE. Physics for Radiation Protection. Wiley; 2013

57. Feldman LC, Mayer JW. Fundamentals of Surface and Thin Film Analysis. Prentice Hall PTR; 1986.

58. McMahon SJ, Hyland WB, Muir MF, Coulter JA, Jain S, Butterworth KT, et al. Biological consequences of nanoscale energy deposition near irradiated heavy atom nanoparticles. Sci Rep. 2011; 1: 18.

59. Douglass M, Bezak E, Penfold S. Monte Carlo investigation of the increased radiation deposition due to gold nanoparticles using kilovoltage and megavoltage photons in a 3D randomized cell model. Med Phys. 2013; 40: 071710 .

60. Xing H, Zheng X, Ren Q, Bu W, Ge W, Xiao Q, et al. Computed tomography imaging-guided radiotherapy by targeting upconversion nanocubes with significant imaging and radiosensitization enhancements. Sci Rep. 2013; 3: 1751.

61. Klein S, Dell'Arciprete ML, Wegmann M, Distel LV, Neuhuber W, Gonzalez $\mathrm{MC}$, et al. Oxidized silicon nanoparticles for radiosensitization of cancer and tissue cells. Biochem Biophys Res Commun. 2013; 434: 217-22.

62. Scarboro SB, Followill DS, Howell RM, Kry SF. Variations in photon energy spectra of a 6 MV beam and their impact on TLD response. Med Phys. 2011; 38: 2619-28.

63. Lechtman E, Chattopadhyay N, Cai Z, Mashouf S, Reilly R, Pignol JP. Implications on clinical scenario of gold nanoparticle radiosensitization in regards to photon energy, nanoparticle size, concentration and location. Phys Med Biol. 2011; 56: 4631-47.

64. Meesungnoen J, Jay-Gerin JP, Filali-Mouhim A, Mankhetkorn S. Low-energy electron penetration range in liquid water. Radiat Res. 2002; 158: 657-60.

65. Dufort S, Sancey L, Coll JL. Physico-chemical parameters that govern nanoparticles fate also dictate rules for their molecular evolution. Adv Drug Delivery Rev. 2012; 64: 179-89.

66. Fan $\mathrm{W}$, Shen $\mathrm{B}, \mathrm{Bu} \mathrm{W}$, Zheng $\mathrm{X}, \mathrm{He} \mathrm{Q}$, Cui Z, et al. Design of an intelligent sub-50 nm nuclear-targeting nanotheranostic system for imaging guided intranuclear radiosensitization. Chem Sci. 2015; 6: 1747-53.

67. Chattopadhyay N, Cai Z, Pignol JP, Keller B, Lechtman E, Bendayan R, et al. Design and characterization of HER-2-targeted gold nanoparticles for enhanced X-radiation treatment of locally advanced breast cancer. Mol Pharm. 2010; 7: 2194-206.

68. Conde J, Doria G, Baptista P. Noble metal nanoparticles applications in cancer. J Drug Deliv. 2012; 2012: 751075.

69. Chen W. Nanoparticle Self-Lighting Photodynamic Therapy for Cancer Treatment. J Biomed Nanotechnol. 2008; 4: 369-76.

70. Liu Y, Chen W, Wang S, Joly AG. Investigation of water-soluble x-ray luminescence nanoparticles for photodynamic activation. Appl Phys Lett. 2008; 92.

71. Morgan NY, Kramer-Marek G, Smith PD, Camphausen K, Capala J. Nanoscintillator conjugates as photodynamic therapy-based radiosensitizers: calculation of required physical parameters. Radiat Res. 2009; 171: 236-44.

72. Scaffidi JP, Gregas MK, Lauly B, Zhang Y, Vo-Dinh T. Activity of psoralen-functionalized nanoscintillators against cancer cells upon X-ray excitation. ACS nano. 2011; 5: 4679-87

73. Bulin A-L, Truillet C, Chouikrat R, Lux F, Frochot C, Amans D, et al. X-ray-Induced Singlet Oxygen Activation with Nanoscintillator-Coupled Porphyrins. J Phys Chem C. 2013; 117: 21583-9.

74. Zhang C, Zhao K, Bu W, Ni D, Liu Y, Feng J, et al. Marriage of scintillator and semiconductor for synchronous radiotherapy and deep photodynamic therapy with diminished oxygen dependence. Angew Chem Int Ed Engl. 2015; 54: $1770-4$

75. Bulin AL, Vasil'ev A, Belsky A, Amans D, Ledoux G, Dujardin C. Modelling energy deposition in nanoscintillators to predict the efficiency of the X-ray-induced photodynamic effect. Nanoscale. 2015

76. Jain S, Coulter JA, Butterworth KT, Hounsell AR, McMahon SJ, Hyland WB, et al. Gold nanoparticle cellular uptake, toxicity and radiosensitisation in hypoxic conditions. Radiother Oncol. 2014; 110: 342-7.

77. Fan W, Shen B, Bu W, Chen F, Zhao K, Zhang S, et al. Rattle-structured multifunctional nanotheranostics for synergetic chemo-/radiotherapy and simultaneous magnetic/luminescent dual-mode imaging. J Am Chem Soc. 2013; 135: 6494-503.

78. Fan $\mathrm{W}$, Shen $\mathrm{B}, \mathrm{Bu} \mathrm{W}$, Chen $\mathrm{F}, \mathrm{He} \mathrm{Q}$, Zhao $\mathrm{K}$, et al. A smart upconversion-based mesoporous silica nanotheranostic system for synergetic chemo-/radio-/photodynamic therapy and simultaneous MR/UCL imaging. Biomaterials. 2014; 35: 8992-9002.

79. Xiao F, Zheng $\mathrm{Y}$, Cloutier $\mathrm{P}, \mathrm{He} \mathrm{Y}$, Hunting D, Sanche L. On the role of low-energy electrons in the radiosensitization of DNA by gold nanoparticles. Nanotechnology. 2011; 22: 465101

80. Xing JZ, Xiaoyan Y, Jie C, Biao H, Roa W. Electronic dynamic cellular sensor used to measure gold nanoparticles enhanced radiotherapy. Life Science Systems and Applications Workshop (LiSSA), 2011 IEEE/NIH. 2011: 20-3. 
81. Butterworth KT, Coulter JA, Jain S, Forker J, McMahon SJ, Schettino G, et al. Evaluation of cytotoxicity and radiation enhancement using $1.9 \mathrm{~nm}$ gold particles: potential application for cancer therapy. Nanotechnology. 2010; 21: 295101.

82. Hainfeld JF, Dilmanian FA, Zhong Z, Slatkin DN, Kalef-Ezra JA, Smilowitz HM. Gold nanoparticles enhance the radiation therapy of a murine squamous cell carcinoma. Phys Med Biol. 2010; 55: 3045-59.

83. Porcel E, Liehn S, Remita H, Usami N, Kobayashi K, Furusawa Y, et al. Platinum nanoparticles: a promising material for future cancer therapy? Nanotechnology. 2010; 21: 85103.

84. Rahman WN, Wong CJ, Yagi N, Davidson R, Geso M. Dosimetry And Its Enhancement Using Gold Nanoparticles In Synchrotron Based Microbeam And Stereotactic Radiosurgery. AIP Conference Proceedings. 2010; 1266: 107-10.

85. Withers NJ, Plumley JB, Triño ND, Sankar K, Akins BA, Rivera AC, et al. Scintillating-nanoparticle-induced enhancement of absorbed radiation dose. SPIE Proceedings; 2009: 718917-8.

86. Liu CJ, Wang CH, Chien CC, Yang TY, Chen ST, Leng WH, et al. Enhanced $\mathrm{x}$-ray irradiation-induced cancer cell damage by gold nanoparticles treated by a new synthesis method of polyethylene glycol modification. Nanotechnology. 2008; 19: 295104.

87. Kaur H, Pujari G, Semwal MK, Sarma A, Avasthi DK. In vitro studies on radiosensitization effect of glucose capped gold nanoparticles in photon and ion irradiation of HeLa cells. Nucl Instrum Methods Phys Res, Sect B. 2013; 301: 7-11.

88. Wang C, Li X, Wang Y, Liu Z, Fu L, Hu L. Enhancement of radiation effect and increase of apoptosis in lung cancer cells by thio-glucose-bound gold nanoparticles at megavoltage radiation energies. J Nanopart Res. 2013; 15: 1-12.

89. Bobyk L, Edouard M, Deman P, Vautrin M, Pernet-Gallay K, Delaroche J, et al. Photoactivation of gold nanoparticles for glioma treatment. Nanomedicine. 2013; 9: 1089-97.

90. Alqathami M, Blencowe A, Yeo UJ, Franich R, Doran S, Qiao G, et al. Enhancement of radiation effects by bismuth oxide nanoparticles for kilovoltage $\mathrm{x}$-ray beams: A dosimetric study using a novel multi-compartment 3D radiochromic dosimeter. J Phys Conf Ser. 2013; 444: 012025.

91. Joh DY, Sun L, Stangl M, Al Zaki A, Murty S, Santoiemma PP, et al. Selective targeting of brain tumors with gold nanoparticle-induced radiosensitization. PLOS ONE. 2013; 8: e62425.

92. Briggs A, Corde S, Oktaria S, Brown R, Rosenfeld A, Lerch M, et al. Cerium oxide nanoparticles: influence of the high- $Z$ component revealed on radioresistant 9L cell survival under X-ray irradiation. Nanomedicine. 2013; 9: 1098-105.

93. Cho SH, Jones BL, Krishnan S. The dosimetric feasibility of gold nanoparticle-aided radiation therapy (GNRT) via brachytherapy using low-energy gamma-/ $\mathrm{x}$-ray sources. Phys Med Biol. 2009; 54: 4889-905.

94. Jones BL, Krishnan S, Cho SH. Estimation of microscopic dose enhancement factor around gold nanoparticles by Monte Carlo calculations. Med Phys. 2010; 37: 3809-16.

95. Berbeco RI, Ngwa W, Makrigiorgos GM. Localized dose enhancement to tumor blood vessel endothelial cells via megavoltage X-rays and targeted gold nanoparticles: new potential for external beam radiotherapy. Int J Radiat Oncol Biol Phys. 2011; 81: 270-6.

96. Garnica-Garza HM. Treatment planning considerations in contrast-enhanced radiotherapy: energy and beam aperture optimization. Phys Med Biol. 2011; 56: 341-55.

97. McMahon SJ, Hyland WB, Muir MF, Coulter JA, Jain S, Butterworth KT, et al. Nanodosimetric effects of gold nanoparticles in megavoltage radiation therapy. Radiother Oncol. 2011; 100: 412-6.

98. Perez-Lopez CE, Garnica-Garza HM. Monte Carlo modeling and optimization of contrast-enhanced radiotherapy of brain tumors. Phys Med Biol. 2011; 56: 4059-72.

99. Chow JC, Leung MK, Jaffray DA. Monte Carlo simulation on a gold nanoparticle irradiated by electron beams. Phys Med Biol. 2012; 57: 3323-31.

100. Ngwa W, Makrigiorgos GM, Berbeco RI. Gold nanoparticle enhancement of stereotactic radiosurgery for neovascular age-related macular degeneration. Phys Med Biol. 2012; 57: 6371-80.

101. Detappe A, Tsiamas P, Ngwa W, Zygmanski P, Makrigiorgos M, Berbeco R. The effect of flattening filter free delivery on endothelial dose enhancement with gold nanoparticles. Med Phys. 2013; 40: 031706.

102. Garnica-Garza HM. Monte Carlo modeling of converging small-field contrast-enhanced radiotherapy of prostate. Phys Med. 2013; 29: 493-9.

103. Mesbahi A, Jamali F, Garehaghaji N. Effect of photon beam energy, gold nanoparticle size and concentration on the dose enhancement in radiation therapy. BI. 2013; 3: 29-35.

104. Tsiamas P, Liu B, Cifter F, Ngwa WF, Berbeco RI, Kappas C, et al. Impact of beam quality on megavoltage radiotherapy treatment techniques utilizing gold nanoparticles for dose enhancement. Phys Med Biol. 2013; 58: 451-64.

105. Tu S-J, Yang P-Y, Hong J-H, Lo C-J. Quantitative dosimetric assessment for effect of gold nanoparticles as contrast media on radiotherapy planning. Rad Phys Chem. 2013; 88: 14-20. 